\title{
Formação docente: um exercício de autonomia colaborativa
}

\author{
Marco Antônio Sandini Trentin ${ }^{1,}$ Adriano Canabarro Teixeira ${ }^{1}$, Ana \\ Carolina Bertoletti de Marchi ${ }^{1}$, Maria Célia Rossetto ${ }^{2}$ \\ ${ }^{1}$ Curso de Ciência da Computação, ${ }^{2}$ Faculdade de Educação - Universidade de Passo \\ Fundo (UPF), Caixa Postal 611 - 99010-970 - Passo Fundo - RS - Brasil \\ \{trentin, teixeira, carolina, mceliarossetto\} dupf.br
}

Resumo: Este artigo tem por objetivo verificar a potencialidade de uma metodologia de formação docente baseada no conceito de inclusão digital, através da implementação de um projeto piloto com professores de escolas da rede de ensino pública municipal da cidade de Passo Fundo/RS. Para tanto, realizou-se um refinamento teórico-conceitual em torno dos elementos chave, a implementação e análise de projetos de aprendizagem. Tais processos culminaram em uma proposta de formação docente, que tem os resultados de sua execução apresentados e analisados neste artigo.

Palavras-chave: inclusão digital, formação docente, software-livre.

\section{Teacher formation: an exercise of colaborative autonomy}

Abstract: The goal of this paper is to verify the potenciality of a methodology of teacher formation based on the digital inclusion concept, through the implementation of a pilot project with teachers from the municipal schools of Passo Fundo city in the state of Rio Grande do Sul. With that purpose, a theoretical and conceptual refinement around the key elements was accomplished, as well as the implementation and analysis of projects of learning. Such processes turned into a proposal for teacher training, whose results are presented and analysed in this paper.

Keywords: - digital inclusion, teacher formation, free software

\section{Introdução}

As tecnologias contemporâneas possuem características que potencializam processos comunicacionais e colaborativos, elementos fundamentais à aprendizagem. Partindo desse princípio, é fundamental que se proponham alternativas teoricamente sustentadas e que considerem o potencial das redes.

Paralelamente, destaca-se ainda, o crescente processo de informatização dos ambientes educacionais, e a deficiência generalizada na formação docente para atuar com as tecnologias, em uma perspectiva de apropriação e de criação de cultura de redes.

Desta forma, acredita-se ser fundamental fomentar reflexões e implementar iniciativas de formação docente, que pressuponham esta apropriação das tecnologias de rede em uma dimensão colaborativa e enquanto ambientes propícios ao desenvolvimento de projetos de aprendizagem.

Este artigo tem por objetivo apresentar e verificar a potencialidade de uma metodologia de formação docente baseada no conceito de inclusão digital, através 
de um projeto piloto com professores de escolas da rede pública de ensino da cidade de Passo Fundo. Inicialmente será apresentado um refinamento teórico-conceitual em torno do conceito de redes. Após, serão levantadas algumas questões com relação à formação docente, passando em seguida para um estudo da importância da inclusão digital na definição de uma metodologia para o projeto de formação proposto. Por fim, serão analisados os resultados obtidos com o projeto piloto.

\section{Alguns elementos da Sociedade Contemporânea: explorando nós da rede}

Ao refletir sobre experiências realizadas no campo potencialmente imbricado da tecnologia e da educação, é fundamental que se discuta o papel desempenhado por cada um destes fenômenos sociais, a partir do contexto social contemporâneo.

Dois elementos são importantes para esta contextualização inicial, o primeiro se refere ao potencial das TIC no processo de disponibilização de informações e o segundo ao valor crescente do conhecimento como fator fundamental ao desenvolvimento humano e social. A partir deste cenário, é freqüente a vinculação entre abundância de informações e possibilidade de ampliação do conhecimento.

Entretanto, é preciso que se reconheça que tais informações, fragmentadas e descontextualizadas, não se caracterizam como conhecimento, uma vez que este demanda processos de reflexão individual e coletiva, de formação e troca de sentidos, todos fundamentais ao processo de aprendizagem, elemento central no conceito de Sociedade proposto por Fróes (2003). Buscando aprofundar o entendimento da sociedade, encontram-se alguns elementos de apoio no conceito de Cibercultura apresentado por Lemos (2002). Para o autor, cibercultura é a cultura contemporânea como conseqüência direta da evolução da cultura técnica moderna.

Marcada pelas tecnologias digitais, a cibercultura permeia o cotidiano das pessoas que convivem e se fundem com as tecnologias disponíveis, fazendo de celulares e palms, extensões de seus próprios corpos e de homebankings e cartões inteligentes elementos comuns ao seu dia-a-dia. Desta forma, independentemente de termos acesso, enquanto integrantes da sociedade, estamos imersos em uma configuração social repleta de tecnologias, sendo continuamente modificados por elas ao tempo em que também as modificamos. O desejo é que essas modificações ocorram por meio de sujeitos autônomos, críticos e que efetivamente trabalhem colaborativamente e assim respondam aos propósitos da cibercultura.

Fundada em características reticulares, a cibercultura libera os pólos de emissão, possibilitando que cada indivíduo seja um potencial e permanente emissor e receptor de informações, independente do local onde se encontre. Fundamentalmente, a cibercultura busca romper com a lógica de distribuição broadcast das mídias de massa, na medida em que se constrói a partir de um dos conceitos chave da sociedade contemporânea, o conceito de rede.

A lógica das redes, potencializada pelo alto nível de conexão da sociedade, faz com que cada indivíduo esteja não somente conectado, mas seja um potencial nó da trama, transitando por uma fronteira entre o humano e o tecnológico. Dentro desta realidade de conexão generalizada, fortalece-se o conceito de Hipertexto, que segundo Lévy (1993), não dá conta somente da comunicação, mas dos processos sociotécnicos que, assim como vários outros fenômenos têm uma forma hipertextual. Assim, uma vez que possibilita intensos processos comunicacionais, 
potencializando dinâmicas culturais baseadas no compartilhamento e na cooperação, o hipertexto se apresenta como elemento de ligação entre as idéias propostas de Sociedade da Aprendizagem e de Cibercultura.

Entretanto, é preciso que se amplie a contextualização acima, a partir da análise de outra realidade na sociedade contemporânea. Neste sentido, as idéias apresentadas por Santos (2004) em especial o conceito de Globalização que propõe, representam um bom ponto de partida para que se possa refletir sobre propostas de ação na área de Informática Educativa como formas essencialmente de inclusão.

Neste sentido, é preciso reconhecer que, mais do que conectar equipamentos, conectam-se culturas, contextos de aprendizagem diferenciados, alargando as possibilidades de trocas e de crescimento sócio-cultural, mas também criando um novo território, aberto e indefinido, sujeito à manipulação de informações, à imposição cultural, à incitação para o consumo e as influências externas.

Incompatível com as características da cibercultura e contrariamente às possibilidades de emissão e de criação que as tecnologias de rede trazem em si, verifica-se um esforço no sentido de lhes imprimir o tradicional modelo centrado na recepção, no consumo e na reprodução, procurando fazer com que cada indivíduo se torne um consumidor potencial, constantemente acessível à ação do mercado, reduzindo-as desta forma a tecnologias de recepção.

Dentro desta dinâmica, são propostos mecanismos que asseguram aos indivíduos condições de manipular as tecnologias de acesso ao novo território globalizado do mercado através de processos de capacitação que impõem e reforçam a cultura passiva da recepção e da reprodução.

É preciso que se reconheça que a grande maioria da sociedade já está imersa de fato e ideologicamente na cultura digital do consumo, da recepção e da passividade, também presente no espaço escolar. Esta situação é acentuada por iniciativas de pseudo-inclusão digital baseadas na reprodução, na falta de criatividade e na negação da reticularidade das tecnologias contemporâneas, portanto, desvinculadas de qualquer compromisso social com a criação de uma cultura tecnológica fundada na lógica das redes.

Embora se reconheça a não neutralidade das tecnologias dada sua intencionalidade geradora, as Tecnologias de Rede (TR) possuem características revolucionárias em relação às suas antecessoras, na medida em que trazem em si a potencialidade das redes, permitindo uma apropriação diferenciada, pautada na criticidade, na criatividade e na autoria colaborativa.

Assim, propõe-se a ampliação do conceito de inclusão digital para uma dimensão reticular e hipertextual, caracterizando-o como um processo horizontal. Esse deve acontecer a partir do interior dos grupos visando à re-apropriação crítica e criativa das TIC, em uma perspectiva que considere processos de interação, de construção de autonomia, de ampliação da cultura e de valorização da diversidade.

\subsection{As Tecnologias de Rede: a questão da formação docente}

A possibilidade de fomentar e construir na região um processo de informática educativa que contemple as TR e o contexto sócio-cultural, numa 
relação e construção dialógica, motivou o grupo de pesquisa de Informática na Educação da UPF a procurar espaços de trabalho nas redes de ensino.

O ensino, de modo geral, tende a reproduzir um modelo de educação que acentua o distanciamento entre as TR e o processo de formação escolar, numa dinâmica que pouco contribui para a tarefa de fomentar o desenvolvimento da autonomia numa cultura de rede. Parte-se do princípio de que a escola é centrada em uma pedagogia de distribuição, e que, em assumindo um modelo vertical e hierarquizado também contribui para um tipo de manutenção social. Embora não se possa fazer uma relação direta entre presença de tecnologias e incremento de interatividade e qualidade em sala de aula, verifica-se que esta configuração de escola geralmente enquadra as TR em uma lógica rígida, desconectada e vertical, ignorando as características da Cibercultura e, desta forma, não contribuindo para a concretização da Sociedade da Aprendizagem.

Entretanto, em função de sua presença ramificada e do contingente enorme de professores, a escola deve ser seriamente considerada quando se pensa em implementar uma nova forma de inclusão digital cujo objetivo seja romper com as hegemonias da sociedade atual, não somente por ideologia, mas para interromper uma dinâmica que fatalmente encerra um processo de exclusão social insustentável.

Para tanto, é preciso que dentre questões macro se repense a questão fundamental do imbricamento entre formação continuada do docente e TR, na medida em que é urgente "formar professores que não sejam apenas 'usuários' ingênuos das tecnologias, mas profissionais conscientes e críticos que saibam usar suas possibilidades de acordo com a realidade em que atuam" (Barreto, 2001).

Foi neste sentido que o grupo em informática educativa da Universidade de Passo Fundo, em parceria com a Prefeitura Municipal de Passo Fundo, realizou um projeto piloto de formação docente, cuja base conceitual é a inclusão digital. A formação continuada ora proposta tem como característica uma dinâmica interna de retroalimentação do grupo em seus objetivos, procedimentos e inserção cultural tal como a perspectiva possibilitada pelas tecnologias de rede que constantemente trazem os sujeitos para um posicionamento crítico, ativo e reflexivo, tanto na sua ação docente como no exercício da sua cidadania.

\section{A Inclusão digital como fundamento da definição metodológica do projeto piloto de formação docente}

Em abril de 2005 iniciou-se a parceria entre a Universidade de Passo Fundo, através do Curso de Ciência da Computação, e a Secretaria Municipal de Educação de Passo Fundo com vistas à implantação de laboratórios de informática em dez escolas municipais e à implementação de um projeto piloto de formação docente.

Todos os laboratórios foram instalados com a distribuição do Kit Escola Livre Kelix ${ }^{1}$, solução tecnológica livre, desenvolvida pelo curso de Ciência da Computação especialmente para iniciativas de inclusão digital e informática educativa.

Em paralelo ao processo de implantação dos laboratórios, iniciou-se a discussão acerca da importância da capacitação de professores das escolas que seriam

\footnotetext{
${ }^{1}$ Mais informações em http://kelix.upf.br
} 
contempladas com esses laboratórios. Em novembro de 2006, iniciou-se um curso de 180 horas, composto por cinco módulos, formatado especificamente para essa demanda.

Com vistas à fomentar uma apropriação criativa das tecnologias, os módulos previam, além da utilização do Kelix, das ferramentas da Internet e do Pacote BrOffice, a Construção de Projetos de Aprendizagem que pudessem explorar as possibilidades que um laboratório de informática pode propiciar na escola.

O primeiro módulo, denominado "Informática Educativa na sociedade contemporânea", teve por objetivo criar uma desestabilização do grupo com relação ao papel e ao potencial das tecnologias de rede no processo de aprendizagem. Assim, através de discussões acerca das características da sociedade contemporânea, foi possível desenvolver discussões que culminassem no reconhecimento das TR como ambientes comunicacionais e que demandam uma compulsória mudança de postura dos agentes do processo de aprendizagem.

Uma vez assumida a necessidade de se reconhecer como autor frente as tecnologias, os três módulos seguintes, buscavam instrumentalizar os professores a fim de que pudessem, na condição de (co)autores, descobrir as possibilidades que as ferramentas oportunizam para a criação de estratégias de aprendizagem em suas escolas. Desta forma, os módulos "Utilização do Kit Escola Livre", "Internet", "Pacote BrOffice" foram trabalhados em uma dinâmica contextual e exploratória. Ou seja, à medida em que se refletia sobre a dinâmica escolar e a partir de possíveis estratégias didáticas, as ferramentas eram exploradas pelos professores que, ora individualmente, ora conjuntamente, conheciam as possibilidades de cada uma e vislumbravam inúmeros desdobramentos e apropriações.

A dinâmica proposta na condução destes três módulos tinha por objetivo possibilitar o reconhecimento de que a apropriação das tecnologias, portanto seu imbricamento ao processo de aprendizagem, deve se dar a partir dos anseios e necessidades dos agentes do processo, em uma perspectiva flexível, contextualizada e horizontal. Também, destaca-se que se buscou transitar o mais longe possível da tradicional aula expositiva caracterizada pela apresentação de recursos e a reprodução do procedimento pelos alunos, a fim de que se vivenciasse um processo aberto, e que se reconhecesse que o laboratório de informática é um espaço de criação, de exploração e de experimentação, ou seja, de aprendizagem.

Por fim, o último módulo, denominado "Construção de projetos de aprendizagem utilizando o Kelix" visava não somente a aplicação prática dos conteúdos em suas escolas, mas, principalmente, dos processos vivenciados nos módulos pelos professores. Para tanto, os professores deveriam se organizar em grupos que contemplassem mais de uma escola e construir projetos de aprendizagem interdisciplinares.

Durante a construção deste projeto, o grupo de pesquisadores realizou vários encontros de orientação com os diferentes grupos e visitas às escolas para acompanhar o desenvolvimento dos projetos. É importante ressaltar que os módulos tinham por objetivo principal o auto-reconhecimento dos professores como protagonistas capazes de propor e executar um projeto sem a intervenção dos pesquisadores. Tal estratégia, propositalmente construída, objetivava o uso das TR como espaços de interação, de construção de identidade, de ampliação da cultura e de valorização da diversidade e, principalmente, de autoria e co-autoria. 


\section{Análise dos resultados}

A análise dos resultados da pesquisa visa buscar indícios que venham a comprovar a eficiência da metodologia proposta, e também servirá como ponto de partida para eventuais aprimoramentos e novas frentes de pesquisa.

Para tanto, para a análise dos resultados foram considerados dois aspectos primordiais: a análise qualitativa de dois dos dez projetos desenvolvidos pelos professores nos laboratórios das escolas e a análise do questionário respondido pelos integrantes das turmas de formação docente.

\subsection{Análise dos projetos}

Durante os dois meses em que os professores estiveram envolvidos na elaboração e implantação dos projetos nos laboratórios, foi percebido um grande entusiasmo nos grupos. Vários são os projetos que merecem destaque. Todavia, em especial, podemos destacar dois: "Proposta pedagógica para as séries iniciais utilizando o software Ktuberling" (Lima, 2007) e "Laboratório de Informática: abrindo novas perspectivas no processo de ensino-aprendizagem" (Kirimus, 2007).

O primeiro projeto teve como objetivo promover e analisar uma situação de aprendizagem com o software Ktuberling. Para isso, a proposta pedagógica, dividida em duas etapas, foi aplicada em crianças das séries iniciais de duas escolas municipais.

A primeira etapa foi desenvolvida no laboratório de informática, onde os alunos exploraram o software Ktuberling, em especial "vestindo" uma batata virtual, de forma criativa, objetivando também estimular a espontaneidade, coordenação motora, de forma prazerosa. Nesta etapa, todo o trabalho foi acompanhado pelos pesquisadores do curso de formação docente, através de visitas agendadas.

Na segunda etapa foi solicitado um trabalho similar, porém em sala de aula, com uma batata "real" e diversos tipos de materiais alternativos. Em ambas, ficou evidenciado o processo de autoria colaborativa dos alunos. No primeiro momento, em laboratório, houve euforia e encantamento por parte dos alunos, uma vez que era também o primeiro contato de muitos deles com o computador. A atividade sugerida consistia em completar a "batata virtual" com expressões de alegria, tristeza, diferenças, espanto, e acrescentar acessórios (chapéu, gravata, etc). Algumas crianças apresentaram dificuldades no manuseio do mouse. Com o passar do tempo essas dificuldades foram sendo superadas. As crianças trabalhavam em duplas, em mútua ajuda. Percebeu-se, nessa tarefa, que foram desenvolvidas a motricidade, agilidade, habilidade, criatividade e interação. Já no segundo momento, em sala de aula, a tarefa tinha por objetivo a criação do personagem "cabeça-de-batata". Cada criança fez o seu boneco, com diversos materiais (palitos de fósforo e picolé, botões, EVA, papel colorido, alfinetes, massa de modelar, cordão, copinho de café, cola colorida, etc). Durante essa atividade, surgiram, por parte dos alunos, diversos questionamentos sobre a batata, como por exemplo: que receitas podemos fazer com ela? Quantas batatas são necessárias para fazer uma salada de maionese? Ela pode ser usada como remédio? Pode-se comer a casca? Como se planta e se colhe a batata?

Tal processo gerou na turma diversos projetos de ensino inéditos, que envolveram os alunos e professores em uma efetiva rede de aprendizagem colaborativa.

Por sua vez, no segundo projeto os experimentos foram realizados com duas turmas da $4^{\mathrm{a}}$ série, de duas escolas municipais, presentes em bairros onde a maioria da 
população é de baixa renda. As razões para a escolha dessas turmas foram: portadoras de dificuldades na matemática e na língua portuguesa; caracterizam-se por serem disciplinadas e pouco participativas.

A proposta metodológica do grupo consistia em três momentos interligados: a realização de atividades preparatórias em sala de aula; seguido de atividades no laboratório de informática (explorando os softwares Tuxpaint, Tuxtype, Gcompris e o editor Writer); e retorno as atividades em sala de aula como forma de reflexão, avaliação e encaminhamentos. Dentre as atividades complementares destaca-se a produção, por parte dos alunos, de pequenos textos ao final de cada aula, tecendo comentários a respeito da aprendizagem construída.

Em laboratório foi fornecido o mínimo de orientações, para que os alunos pudessem descobrir por si os recursos possíveis no software. Uma avaliação posterior foi realizada e percebeu-se que em laboratório o aluno pôde melhor demonstrar sua autonomia.

Em ambos os projetos pode-se encontrar uma fundamentação teórica, buscada pelos professores, de forma a direcionar a ação metodológica escolhida em seus projetos coerentemente. Com relação a metodologia desenvolvida ficou evidenciada a autonomia dos alunos e a sensível diferença no engajamento nas atividades propostas em laboratório de informática, em relação à sala de aula.

Por sua vez, durante as visitas realizadas nas escolas para o acompanhamento dos projetos percebeu-se que os professores envolveram-se efetivamente no processo e buscaram subsídios externos aos proporcionados com o uso das tecnologias. Já os alunos mostraram-se radiantes com a possibilidade de utilizar o laboratório de informática da escola e, principalmente, em participarem de uma proposta pedagógica de ensino diferenciada.

\subsection{Análise dos questionários}

De modo a verificar o grau de satisfação dos professores envolvidos em relação à metodologia proposta na formação docente, foi aplicado um questionário de avaliação. Tal questionário foi dividido em três categorias, com perguntas objetivas, que procuravam avaliar a participação/envolvimento do professor enquanto aluno; às práticas didático-pedagógicas da metodologia; e dados referentes ao processo de formação propriamente dito. Além dessas categorias, também foram propostas perguntas descritivas genéricas.

Para o preenchimento das perguntas objetivas, os professores deveriam observar, no local apropriado, a alternativa, de 1 a 5, que melhor expressasse sua opinião, sendo 5 a de maior nota. Na Tabela 1 apresentamos a abrangência das notas que o professor poderia atribuir. 
Tabela 1 - Abrangência das notas do instrumento de avaliação

\begin{tabular}{l|l|l|l|l|l}
\hline Nota & \multicolumn{5}{|c}{ Significados } \\
\hline 1 & Péssimo/péssima & Nunca & Discorda plenamente & Altamente insatisfatória & Não \\
\hline 2 & Ruim & Poucas vezes & Discorda em partes & Insatisfatória & - \\
\hline 3 & Regular & $\begin{array}{l}\text { Cerca da } \\
\text { metade das } \\
\text { vezes }\end{array}$ & $\begin{array}{l}\text { Não concorda nem } \\
\text { discorda }\end{array}$ & Neutra & - \\
\hline 4 & Bom/Boa & Muitas vezes & Concorda em partes & Satisfatória & - \\
\hline 5 & Excelente & Sempre & Concorda plenamente & Muito satisfatória & Sim \\
\hline
\end{tabular}

Assim, cada questão possuía cinco alternativas de respostas, as quais foram associadas notas. A Tabela 2 demonstra um exemplo de questão, com as alternativas de respostas.

Tabela 2 - Exemplo de questão da categoria ambiente

\begin{tabular}{|c|c|c|c|c|c|}
\hline Questão & 1 & 2 & 3 & 4 & 5 \\
\hline $\begin{array}{l}\text { Quanto às práticas didático-pedagógicas, os professores estabeleceram integração } \\
\text { entre teoria e prática dos conteúdos trabalhados? }\end{array}$ & & & & & \\
\hline
\end{tabular}

O questionário foi respondido por cerca de $50 \%$ dos professores presentes na primeira turma do curso. A média geral das três categorias do questionário ficou em 4,39, o que demonstra a aceitação da metodologia proposta. As médias individuais das categorias podem ser visualizadas no gráfico da Figura 1.

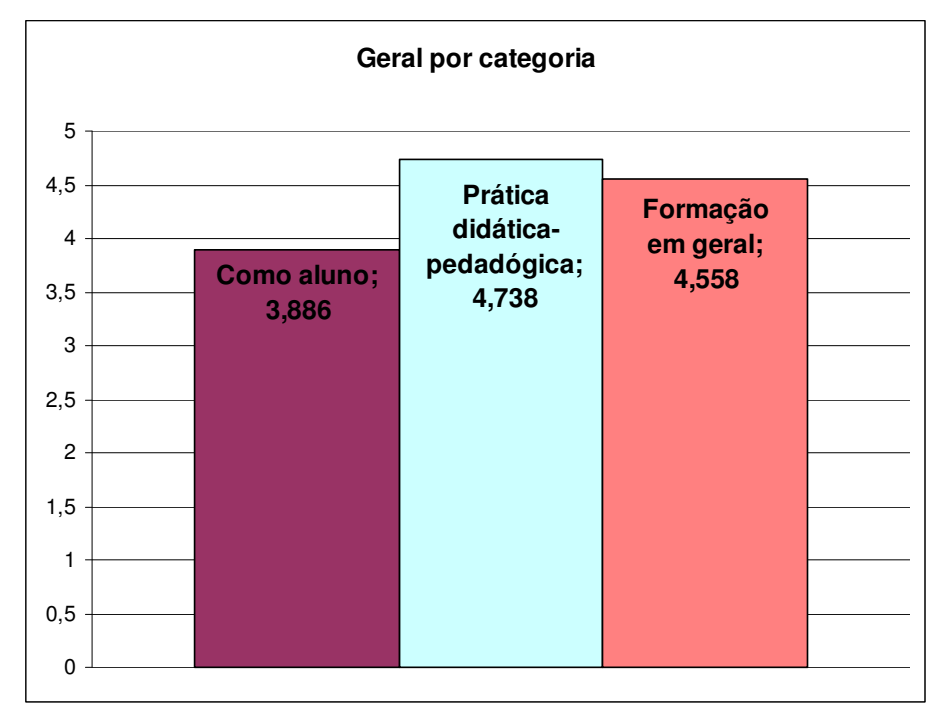

Figura 1 - Média geral por categoria

No gráfico da Figura 2 podemos observar a média individual das questões em cada categoria. Com base neste gráfico, iremos detalhar as questões centrais relacionadas ao objetivo principal desta pesquisa, a formação docente: um exercício de autonomia colaborativa. 


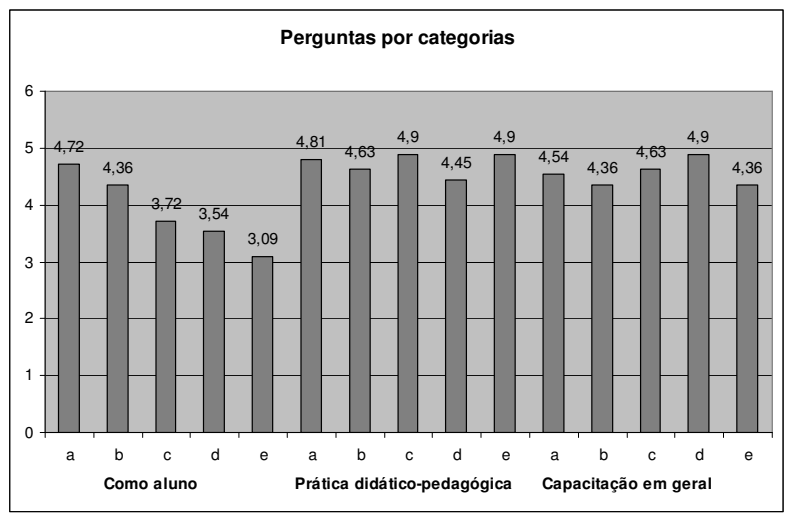

Figura 2 - Média individual das questões por categoria

Neste sentido, de acordo com o gráfico é possível constatar que as médias mais baixas estão relacionadas com a auto-avaliação dos alunos no curso. A questão "e" da categoria "Como aluno": Como aluno, você teve iniciativa em procurar os professores fora do horário de aula, presencialmente ou por correio eletrônico? obteve média 3,09, o que nos permite concluir que os alunos ainda não assumiram totalmente seu papel de protagonistas do processo.

Por sua vez, a questão "e" da categoria "prática didático-pedagógica": Quanto às práticas didático-pedagógicas, os professores estabeleceram integração entre teoria e prática dos conteúdos trabalhados? obteve média 4,9, o que nos fornece indícios da importância de que os professores em formação se apropriem das tecnologias como espaços de desenvolvimento de projetos de aprendizagem interdisciplinares

Por fim, a questão que procurava identificar o quanto à formação docente estava relacionada com o trabalho na escola, obteve média 4,36 (questão "e" da categoria "formação em geral"). Tal resultado nos mostra o quanto à relação teoria-prática foi importante durante a formação. Em alguns questionários essa questão apresentou comentários relacionados ao fato de que muitas escolas ainda não estavam com o laboratório de informática concluído.

Nas questões descritivas, os professores apontaram como maiores problemas enfrentados durante a formação a adaptação dos horários das aulas; a falta de tempo para dedicação, tendo em vista a sobrecarga de trabalho no município; e o pouco conhecimento básico em informática, o que aponta para a necessidade de que os cursos de formação docente atentem para a importância de propiciar momentos de utilização das TR.

Com relação aos aspectos positivos da formação, foram citados: rompimento de resistências com relação ao computador; novos desafios propostos; maior uso efetivo dos laboratórios das escolas; desafio no uso do software livre; crescimento pelo interesse na informática e sua aplicação nas escolas; e interação entre professores da rede municipal de ensino.

Como principal medida sugerida para melhoria da formação, os pesquisadores sugeriram uma mudança na ordem dos módulos, de modo que o último módulo, Projeto de Aprendizagem, fosse realizado durante todo o período de formação. 


\section{Considerações Finais}

Com vistas a refletir acerca dos resultados parciais desta pesquisa, é possível apontar para a pertinência da metodologia proposta na resignificação da informática educativa para os professores. Uma vez assumida enquanto espaço essencialmente interdisciplinar e que exige dos professores e alunos uma postura de pró-atividade, de criatividade e criticidade, pode dar suporte a projetos que possibilitam a alunos e professores assumirem a centralidade dos processos de aprendizagem em uma dinâmica reticular, aberta, flexível e articulada com os demais espaços da Escola.

Durante a experiência, outros elementos merecem destaque, dada a sua importância estratégica para a proposta de alternativas de formação docente para uma sociedade imersa em tecnologia. O primeiro diz respeito à urgência de que as licenciaturas atentem para a necessidade de assumir a informática educativa como uma demanda fundamental de professores na sociedade contemporânea e não como um apêndice opcional do processo de formação superior.

O segundo, refere-se à adoção do Kelix como ferramenta do processo. Foi possível constatar a sua pronta resposta às demandas dos professores, sua adaptabilidade e alta competência para processos de inclusão digital e informática educativa, seja nos módulos de formação, seja no dia-a-dia escolar.

Por fim, é fundamental que se reconheça a importância da parceria entre sociedade, poder público e instituições de ensino no sentido de viabilizar o acesso, de questionar e discutir a concepção educacional que permeia as ações na área e, sobretudo, de ampliar reflexões e ações referentes à formação docente, todas com vistas à construção de um processo educacional que possibilite a vivência de uma cultura de rede como elemento fundamental para o exercício da autonomia colaborativa no atual contexto social.

\section{Referências}

BARRETO, Raquel Goulart (Org.), PRETTO, Nelson de Luca et al.. (2001) Tecnologias educacionais e educação à distância: avaliando políticas e práticas. Rio de Janeiro : Quartet.

FRÓES, Teresinha. (2000) Sociedade da informação, sociedade do conhecimento, sociedade da aprendizagem: implicações ético-políticas no limiar do século. In: LUBISCO, Nídia M. L. et al. Informação e informática. Salvador: EDUFBA.

KIRINUS, L. et al. Laboratório de Informática: abrindo novas perspectivas no processo de ensino-aprendizagem. Projeto de aula. Passo Fundo, 2007.

LEMOS, André. (2002) Cibercultura: Tecnologia e vida social na cultura contemporânea. Porto Alegre: Sulina.

LÉVY, Pierre. (1993) As Tecnologias da Inteligência: O Futuro do Pensamento na Era da Informática. Rio de Janeiro: Ed. 34.

LIMA, C.R. et al. Proposta pedagógica para séries iniciais utilizando o software Ktuberling. Projeto de aula. Passo Fundo, 2007.

SANTOS, Milton. (2004) Por uma outra Globalização: do pensamento único à consciência universal. São Paulo, Record. 